\title{
Acetyl Group Determinations in Horse Liver Alcohol Dehydrogenase and in Horse Myoglobin
}

\author{
HA NS Jö R N VA L L \\ Department of Biochemistry, Nobel Medical Institute, Stockholm, Sweden
}

\begin{abstract}
The main fraction of horse liver alcohol dehydrogenase was subjected to acid hydrolysis followed by an enzymatic microdetermination of acetic acid. Extensive dialysis of the pure protein was necessary in order to remove supposedly adsorbed acetate. When this background had been largely removed the value for acetic acid corresponded to about 2 acetyl groups per molecule of protein. Although this method does not give any indication of where these acetyl groups are situated, the failure to demonstrate an $\mathrm{N}$-terminal amino acid strongly suggests that they represent $\mathrm{N}$-terminal groups.

Three fractions of horse skeletal muscle myoglobin were also analysed. In the hydrolysates of two of these it was possible to bring the acetic acid content to nearly zero by extensive dialysis of the pure fractions. In one fraction, however, the acetic acid content could not be lowered to less than $0.5-0.7$ moles per mole of protein. This seems most likely to indicate acetate adsorption. That explanation is also favoured by other considerations as well as by a hydrazinolysis. In any case, it is clearly shown that differences in acetylation status cannot be the explanation for all three myoglobin variants.
\end{abstract}

Tn a previous investigation the author ${ }^{1}$ was unable to find any $\mathrm{N}$-terminal 1 amino acid by the fluorodinitrobenzene method in the main fraction $\left(\mathrm{LADH}_{\mathrm{E}}{ }^{2}\right)$ of horse liver alcohol dehydrogenase. This was verified by Hamburg ${ }^{3}$ using cyanate. It therefore seemed possible that the $\mathrm{N}$-terminal amino groups might be acetylated. That this occurs in proteins was first shown by Narita 4 and has since been demonstrated in many proteins by several workers using different methods. In order to investigate this possibility $\mathrm{LADH}_{\mathrm{E}}$ was subjected to acetyl group determinations.

The three myoglobins ( $\mathrm{Mb} \mathrm{I}, \mathrm{Mb} \mathrm{II}_{1}$, and $\mathrm{Mb} \mathrm{II}_{2}$ ) isolated in this laboratory ${ }^{5}$ have previously been shown ${ }^{5}$ to have, within the experimental errors, the same amino acid composition and amide group content. One of the possible explanations for the heterogeneity was suggested ${ }^{6}$ to be an acetylation of an $\varepsilon$-amino group of a lysine. Therefore the myologbins were also analysed for acetyl groups in this investigation. 


\section{MATERIALS AND METHODS}

$\mathrm{LADH}_{\mathrm{E}}$ was prepared by a modification ${ }^{7}$ of Dalziel's method. ${ }^{8}$ The myoglobins were prepared by the method of Åkeson and Theorell ${ }^{5}$ and were generously supplied by Dr. Akeson. The pure proteins were further subjected to dialyses against different buffers as indicated below. A dialysis buffer/protein solution ratio of 50-300 was used and each dialysis continued for about $20 \mathrm{~h}$. The proteins were then lyophilized.

Pig heart malate dehydrogenase, MDH, was purchased from Boehringer \& Soehne. Citrate synthase (citrate condensing enzyme), CS, was purchased from Boehringer \& Soehne and from Calbiochem. Acetyl-CoA synthetase (acetate-activating enzyme, AAE) was prepared from yeast by the method of Berg. ${ }^{9}$ Coenzyme A and ATP were purchased from Boehringer \& Soehne and NAD from Sigma. All other chemicals were of analytical grade. For the acetic acid determinations redistilled water was used and the handling of the proteins and reagents was performed in a closed room from which acetic acid was excluded.

The enzymatic micromethod for determination of acetate content was originally proposed by von Korff. ${ }^{10}$ The reactions are:

$$
\begin{aligned}
& \text { acetate }+\mathrm{ATP}+\mathrm{CoA} \stackrel{\mathrm{Mg}, \mathrm{AAE}}{\rightleftharpoons} \text { acetyl-CoA }+\mathrm{AMP}+\mathrm{PP} \\
& \text { acetyl-CoA }+ \text { oxaloacetate } \stackrel{\mathrm{CS}}{\longrightarrow} \text { citrate }+\mathrm{CoA} \\
& \text { malate }+\mathrm{NAD}^{+} \stackrel{\mathrm{MDH}}{\rightleftharpoons} \text { oxaloacetate }+\mathrm{NADH}+\mathrm{H}^{+}
\end{aligned}
$$

The acetate in the sample to be tested is thus converted to citrate in reactions (1) and (2). The oxaloacetate needed is produced in reaction (3) with the liberation at the same time of NADH, which is determined photometrically at $340 \mathrm{~nm}$. The acetate content of the sample can then be calculated. However, this amount is not equal to the amount of NADH produced owing to the change in equilibrium concentrations in reaction (3), as was first explained by Pearson. ${ }^{11}$ An excellent guide to the use of this method was given by Bergmeyer and Moellering. ${ }^{12}$ Stegink and Vestling ${ }^{13}$ applied the method to protein hydrolysates and reported the presence of an inhibitor of the reaction obviously created during hydrolysis. In order to avoid this they extracted the acetic acid from the hydrolysates into diethyl ether and then into Tris buffer.

In the present work known amounts of the freeze-dried proteins to be analysed (about 12-16 mg of $\mathrm{LADH}_{\mathrm{E}}$ and 4-8 $\mathrm{mg}$ of $\mathrm{Mb}$ ) were transferred to hydrolysis tubes. $0.4-0.8 \mathrm{ml}$ of sulphuric acid, $2.0-6.4 \mathrm{~N}$, was pipetted into the tubes and hydrolysis performed at $110^{\circ} \mathrm{C}$ for $2-16 \mathrm{~h}$. The tubes were opened after freezing the hydrolysates in acetone/dry ice to prevent evaporation of acetic acid. Tribasic sodium citrate solution was then pipetted into the hydrolysis tube in an amount calculated to bring the content to $2 \mathrm{ml}$ of $0.5 \mathrm{M}, \mathrm{pH} \mathrm{3}$, citrate buffer. After thawing the solution was transferred to a distillation vial according to Bartley ${ }^{14}$ and as suggested by Bergmeyer and Moellering. ${ }^{12}$ The vial was cooled in acetone/dry ice and then evacuated for 90 sec with an ordinary oil pump. After distillation for $2-3 \mathrm{~h}$ it was opened. If not analysed directly, the samples were stored at $-16^{\circ} \mathrm{C}$. The acetate determination was performed largely according to Bergmeyer and Moellering ${ }^{12}$ except that Tris buffer, $\mathrm{pH}$ about 7.6, was used as well as other enzyme amounts: $40 \mu \mathrm{l}$ of $0.5 \mathrm{mg} / \mathrm{ml} \mathrm{MDH}, 20 \mu \mathrm{l}$ of $2 \mathrm{mg} / \mathrm{ml} \mathrm{CS}$, and 20-50 $\mu \mathrm{l}$ of a $1 \mathrm{mg} / \mathrm{ml}$ solution of AAE purified 50 times from the crude extract. 4 cuvettes were run together in a Beckman DU spectrophotometer and the reaction followed at $340 \mathrm{~nm}$. Acetate standards and acetate-free samples were analysed to control the recovery and background. For determination of the unspecific drift the light-absorption of cuvettes without the AAE were followed with time.

Recovery. Direct determinations of acetate standards always gave above $90 \%$ recovery but very seldom over $100 \%$. This is probably due to the fact that the calculations used ${ }^{12}$ depend on a correct amount of malate and NAD in the reagents which can be controlled ${ }^{12}$ after the addition of MDH. An error of a few percent was often found here and might explain the average recovery of about $94 \%$ in direct acetate determination. The total recovery from the hydrolysis vial to the cuvette was found to vary, with the extremes being about 70 and $90 \%$. In this work a recovery of $80 \%$ as an average has been used 
in the calculations. The loss is certainly due, to a large extent, to the several volume transfers without subsequent washing. Furthermore, the citrate added to the hydrolysis tube, or the sulphate used in the distillation, had a background of acetate as reported by von Korff..$^{10}$ The reported inhibitor ${ }^{13}$ might, of course, be one cause of the variability, if it were volatile. This does not seem of great importance, however, as even unhydrolyzed standards showed about the same variation. Minor deviations from $\mathrm{pH} 3$ of the solutions for distillation do not influence the recovery as standards distilled at $\mathrm{pH} 2.8-$ 4.0 gave about the same values. Each hydrolysate was analysed twice using different amounts of the sample and the average value given in the tables. This diminished the influence of acetate content, hypothetical inhibitor/activator compounds, or the corrections used, on the values obtained. The elimination of these influences, together with the agreement in results between the different samples analysed, indicates a nearly accurate value for acetate content.

\section{RESULTS AND DISCUSSION}

\section{Horse liver alcohol dehydrogenase}

Three different preparations were analysed. The mode of hydrolysis and the results are shown in Table 1.

In the first case a preliminary analysis of an $86 \%$ pure (enzymatic activity versus light-absorption at $280 \mathrm{~nm}$ ) LADH-preparation was made to see whether acetyl groups were present. The protein was first dialyzed against 2 changes of water/ammonia, $\mathrm{pH} 9.5$.

The positive finding necessitated analysis of pure ${ }^{7}$ and native $\mathrm{LADH}_{\mathrm{E}}$. After dialysis against 3 changes of water/ammonia, $\mathrm{pH} \mathrm{9}$, part of the freezedried protein was hydrolyzed according to Table 1 and an aliquot placed in the distillation vial, without hydrolysis, and analysed for acetic acid in the usual way.

The third case comprised analysis of another preparation of pure $\mathrm{LADH}_{\mathrm{E}}$. This protein was denatured and the zinc removed by dialysis against $8 \mathrm{M}$ urea in $0.035 \mathrm{M}$ citrate- $\mathrm{HCl}$ buffer, $\mathrm{pH} 4$, followed by: the same buffer without urea, 3 changes of $0.1 \mathrm{M}$ Tris, $\mathrm{pH} 9$, the citrate buffer again, and finally 4 changes of redistilled water with hydrochloric acid added to bring the $\mathrm{pH}$ to 4. After lyophilization the protein was shown to be salt-free and analysed with and without hydrolysis according to Table 1.

Table 1. Residues of acetate found per molecule of $\mathrm{LADH}_{\mathrm{E}}$.

\begin{tabular}{|l|c|c|c|c|c|}
\hline & $\begin{array}{c}\text { Preparation 1 } \\
86 \% \text { LADH }\end{array}$ & \multicolumn{2}{|c|}{$\begin{array}{c}\text { Preparation 2 } \\
\text { native LADH }\end{array}$} & \multicolumn{2}{|c|}{$\begin{array}{c}\text { Preparation 3 } \\
\text { denatured LADH }\end{array}$} \\
\cline { 2 - 5 } \cline { 5 - 6 } & Direct & Direct & $\begin{array}{c}\text { Value without } \\
\text { hydrolysis } \\
\text { subtracted }\end{array}$ & Direct & $\begin{array}{c}\text { Value without } \\
\text { hydrolysis } \\
\text { subtracted }\end{array}$ \\
\hline No hydrolysis & & 1.3 & & 0.2 & \\
2.0 N for 2 h & 16 & 3.6 & 2.3 & 2.1 & 1.9 \\
3.0 N for 4 h & & & & 2.2 & 2.0 \\
3.2 N for 4 h & & & & 2.2 & 2.0 \\
6.4 N for 4 h & 6.4 N for 16 h & & & & 2.3 \\
\hline
\end{tabular}

a This hydrolysate had a slight yellow-brown colour, probably due to decomposition. 
It is evident that the impurities in the $86 \% \mathrm{LADH}$-preparation are of high acetate content. This is not surprising as the protein is prepared from liver. The acetic acid liberated without hydrolysis in preparations two and three probably does not reflect $\mathrm{O}$-acetyl linkages, although these esters are known to be very labile (e.g. Ref. 15). That it should represent $\mathrm{N}$-acetyl linkages is still more improbable. Instead the high acetate content in the impure preparation, and the decrease in acetate content upon urea treatment in the cases of pure $\mathrm{LADH}_{\mathrm{E}}$, strongly suggest that the acetic acid liberated without hydrolysis represents acetate adsorbed onto the protein molecule. In case three even after the dialysis in $8 \mathrm{M}$ urea and lyophilization from a solution at $\mathrm{pH} \mathrm{4}$, which should enhance elimination of acetate, some presumably adsorbed background remains. As the difference in the amount of liberated acetic acid with and without hydrolysis seems to be about the same in cases two and three, the distillation alone obviously gives a reasonably accurate indication of the adsorbed material. In case three the background is very small and the difference, 1.9 to 2.3 moles of acetic acid/mole of $\mathrm{LADH}_{\mathrm{E}}$ with and without hydrolysis, represents 2 acetyl groups covalently bound to the protein molecule. The figures in Table 1 are based on a molecular weight of $84000^{16}$ for $\mathrm{LADH}_{\mathrm{E}}$. The value obtained with the most extensive hydrolysis is slightly higher than the others. A possible reason might be the decomposition which took place as shown by the faint discoloration.

In view of the earlier ${ }^{1,3}$ failures to demonstrate an $\mathrm{N}$-terminal amino acid it seems highly probable that these 2 acetyl groups represent blocking end groups. $\mathrm{LADH}_{\mathrm{E}}$ therefore adds to the now long list of proteins which have acetylated amino acids as $\mathrm{N}$-terminals. The full proof of this requires the demonstration of that amino acid. This was tried in the present analysis by treating a portion of $\mathrm{LADH}_{\mathrm{E}}$ with methanol/hydrochloric acid ${ }^{17}$ and then using fluorodinitrobenzene to find an $\mathrm{N}$-terminal amino acid. The protein chains were, however, split in more places than the supposed acetyl linkages.

The present result fits well with the hypothesis that $\mathrm{LADH}_{\mathrm{E}}$ is composed of $2^{*}$ very similar if not identical ${ }^{18}$ chains, the active sites of which are identical. ${ }^{19,20}$ There are two identical ${ }^{3}$ C-terminals and it has now been shown that two N-terminals obviously are acetylated.

\section{The myoglobins}

All analyses were performed on the ferri-proteins. The results of three different pretreatments are shown in Table 2 . In no case was any acetate found by distillation without hydrolysis.

Mb I: After the most extensive dialysis Mb I had practically no hydrolyzable acetate left. The treatment with urea obviously lowered the acetate content. The possibility that the value 0.6 in the second pretreatment repre-

* Since the acceptance of this paper $\mathrm{LADH}_{\mathrm{E}}$ has been reported from ultracentrifugational data to consist of 4 chains (Drum, D. E., Harrison, IV, J. H. and Li, T.-K. Federation Proc. 26 (1967) 821 and Drum, D. E., Harrison, IV, J. H., Li, T.-K., Bethune, J. L., and Vallee, B. L. Proc. Natl. Acad. Sci. U. S. 57 (1967) 1434). These results are difficult to reconcile with the present data and no explanation of the discrepancies can be suggested without further investigation. 
Table 2. Residues of acetate found per molecule of myoglobin.

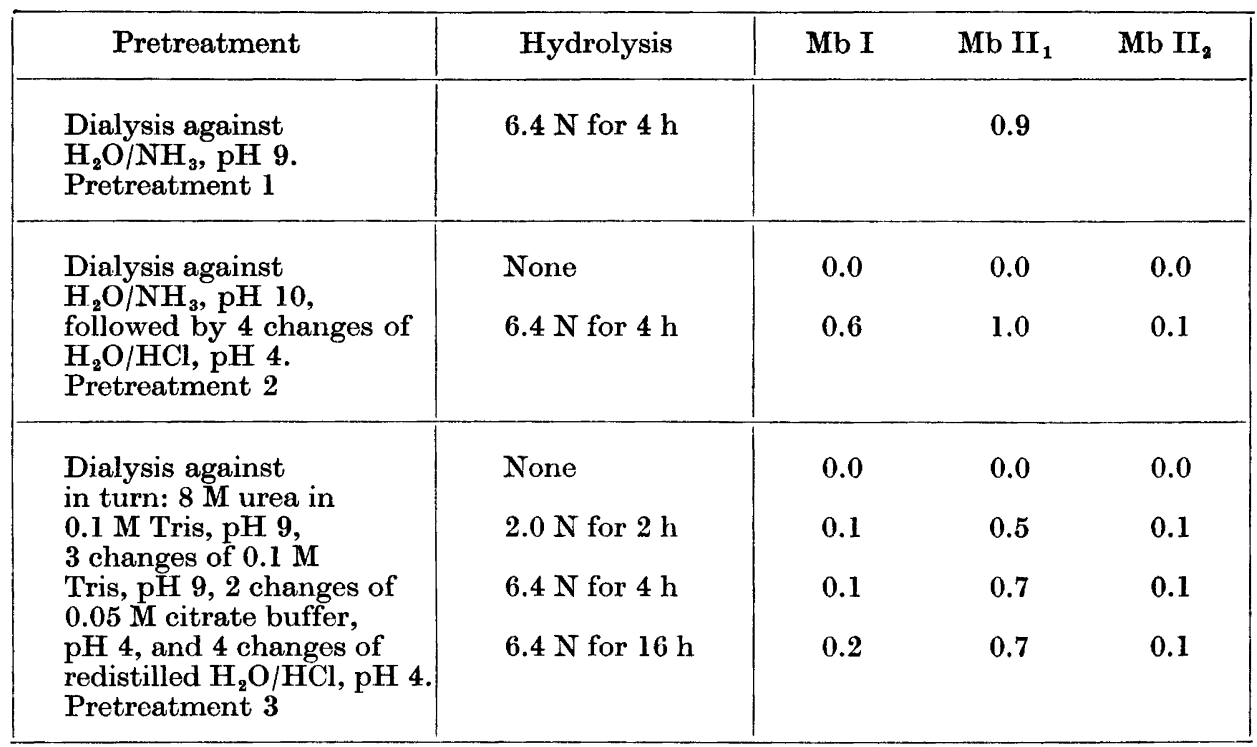

sents a remnant of a labile acetyl group which is nearly totally removed in the third pretreatment can be excluded. The dialysis in the second case was performed at $\mathrm{pH} 4$. If this should partially remove a labile group the distillation (at $\mathrm{pH} \mathrm{3)}$ without hydrolysis would certainly do the same. As, however, no acetate was found without hydrolysis the presence of a labile acetyl group is very unlikely. It is probable that the acetate in the second analysis represents a contamination or adsorption as was the case in the analyses on $\mathrm{LADH}_{\mathrm{E}}$. $\mathrm{Mb} \mathrm{I}$ is thus free of acetyl groups.

$M b I I_{1}$ : In this myoglobin variant the acetate found could conceivably be thought to represent one acetyl group per molecule. There is, however, a decline from pretreatment two to three which is of the same order of magnitude as for $\mathrm{Mb} \mathrm{I}$. This suggests that even in $\mathrm{Mb} \mathrm{II}_{1}$ the acetate found represents some contamination, which, however, sticks unusually firmly to the protein. Ordinary dialyses seem unable to remove all acetate from this fraction. A labile acetyl group is improbable on the same grounds as for $\mathrm{Mb}$ I. A covalently bound acetyl group can, however, not be totally excluded on the basis of only these analyses. The presence of such a group has been shown ${ }^{21}$ to be the difference between hemoglobin $\mathrm{F}_{\mathrm{I}}$ and $\mathrm{F}_{\mathrm{II}}$. In this case and in other acetylated hemoglobins, ${ }^{22}$ however, it is the $\mathrm{N}$-terminal amino group which is acetylated. The myoglobins have all been shown ${ }^{5}$ to have free $\mathrm{N}$-terminal glycine. To study this question further a single hydrazinolysis to detect $\mathrm{O}$ - and $\mathrm{N}$-acetyl groups according to Phillips ${ }^{23}$ was performed. The proteins were dialyzed as in pretreatment three, Table 2, before analyses. The chromatograms of the products from $\mathrm{Mb} \mathrm{II}$ and $\mathrm{II}_{2}$ looked the same. Both differed from the chroma-

Acta Chem. Scand. 21 (1967) No. 7 
tograms obtained from the products of $\mathrm{LADH}_{\mathrm{E}}$, where a spot corresponding to the acetyl derivative was found. The recoveries were, however, not determined and the quantification therefore uncertain. A very low recovery is, however, needed not to detect an acetyl group. The result thus favours the above conclusion that $\mathrm{Mb} \mathrm{II}_{1}$ has no covalently bound acetyl groups.

$\mathrm{Mb} \mathrm{II} 2: \mathrm{Mb} \mathrm{II}_{2}$ contains no acetyl groups.

It thus seems most probable that the acetate contents found in this work reflect different tendencies to ionic binding of the myoglobin variants. That strong adsorption of anions takes place in myoglobins is shown by Gillespie et $a .^{24}$ in the case of sperm whale metmyoglobin and phosphate $(0.5-1.5$ moles of phosphate/mole of protein). They also showed that the different fractions of myoglobin did not have the same affinities for ions.

The results clearly indicate that acetylation is not the reason for the difference between the three myoglobins. The hypothesis that acetyl groups should constitute the difference between $\mathrm{Mb} \mathrm{II}_{1}$ and one of the other fractions neither seems probable in view of the results. Another explanation to the difference must then be sought. If the acetate found represents ionic binding as suggested above, the implications with respect to the earlier protein titration curve ${ }^{6}$ and perhaps also the amide content ${ }^{5}$ should be considered. Amide groups might again be suspected to constitute the difference between these myoglobin variants in analogy with the similar heterogeneity patterns of sperm whale myoglobin, ${ }^{25}$ cytochrome $c^{26}$ and lactoperoxidase. ${ }^{27}$

Acknowledgements. The author wishes to express his thanks to Professor H. Theorell for his great interest and helpful advices. The discussions with Drs. $\AA$. A keson and A. Carlström are greatly appreciated. Dr. T. Moss is thanked for reviewing the English. This work was supported by a grant from Karolinska Institutet.

\section{REFERENCES}

1. Jörnvall, H. Acta Chem. Scand. 19 (1965) 1483.

2. Theorell, H., Taniguchi, S., Åkeson, Å. and Skurský, L. Biochem. Biophys. Res. Commun. 24 (1966) 603.

3. Hamburg, R. D. The Physical Properties of Horse Liver Alcohol Dehydrogenase (Diss.), University of California, Berkeley 1966.

4. Narita, K. Biochim. Biophys. Acta 28 (1958) 184.

5. Åkeson, Å. and Theorell, H. Arch. Biochem. Biophys. 91 (1960) 319.

6. Åkeson, Å. Studies on Myoglobin (Diss.), Caroline Inst., Stockholm 1962.

7. Taniguchi, S., Theorell, H. and Åkeson, A. Acta Chem. Scand. 21 (1967) 1903.

8. Dalziel, K. Acta Chem. Scand. 12 (1958) 459.

9. Berg, P. J. Biol. Chem. 222 (1956) 991.

10. von Korff, R. W. J. Biol. Chem. 210 (1954) 539.

11. Pearson, D. J. Biochem. J. 95 (1965) 23c.

12. Bergmeyer, H. U. and Moellering, H. Biochem. Z. 344 (1966) 167.

13. Stegink, L. D. and Vestling, C. S. J. Biol. Chem. 241 (1966) 4923.

14. Bartley, W. Biochem. J. 53 (1953) 305.

15. Uraki, Z., Terminiello, L., Bier, M. and Nord, F. F. Arch. Biochem. Biophys. 69 (1957) 644 .

16. Ehrenberg, A. Acta Chem. Scand. 11 (1957) 1257.

17. Margoliash, E., Smith, E. L., Kreil, G. and Tuppy, H. Nature 192 (1961) 1121.

18. Brändén, C.-I. Arch. Biochem. Biophys. 112 (1965) 215. 
19. Harris, I. Nature 203 (1964) 30.

20. Li, T.-K. and Vallee, B. L. Biochemistry 3 (1964) 869.

21. Schroeder, W. A., Cua, J. T., Matsuda, G. and Fenninger, W. D. Biochim. Biophys. Acta 63 (1962) 532.

22. Braunitzer, G. J. Cell. Physiol. 67 Suppl. 1 (1966) 1.

23. Phillips, D. M. P. Biochem. J. 86 (1963) 397.

24. Gillespie, J. M., Hapner, K. D., Hartzell, C. R. and Gurd, F. R. N. J. Mol. Biol. 21 (1966) 399.

25. Edmundson, A. B. Nature 205 (1965) 883.

26. Flatmark, T. Acta Chem. Scand. 20 (1966) 1476.

27. Carlström, A. Acta Chem. Scand. 20 (1966) 1426.

Received April 1, 1967. 